\title{
Increasing Scopolamine content in Hairy Roots of Atropa belladonna using Bioreactor
}

\author{
Peyman Habibi ${ }^{1}$, Khosro Piri ${ }^{1 *}$, Ali Deljo ${ }^{1}$, Yaser Ahmadi Moghadam ${ }^{1}$ and Taiebeh \\ Ghiasvand $^{1}$ \\ Department of Biotechnology; Department of Agriculture; Bu-Ali Sina University; Hamedan - Iran
}

\begin{abstract}
The aim of this study was to use the, hairy root system for increasing the scopolamine content in Atropa belladonna. Agrobacterium rhizogenes ATCC15834 was utilized to produce hairy roots. The culture was carried out in a 1.5-l bioreactor using the inoculum size of $0.5 \mathrm{~g} \mathrm{fr}$. wt of 10-day-old hairy roots and various parameters, including agitation, aeration, conductivity and the consumption of sucrose were evaluated. Results revealed that the highest amount of scopolamine production $\left(1.59 \mathrm{mg} / \mathrm{g}^{-1}\right.$ dry wt) occurred in the bioreactor with aeration and agitation 1.25 vvm (volume per volume per minute) and $70 \mathrm{rpm}$, respectively. Study of conductivity and the consumption of sucrose showed that the highest amount of sucrose consumption and the highest amount of minerals consumption also was at $1.25 \mathrm{vvm}$ and $70 \mathrm{rpm}$. Transgenic hairy root lines were confirmed by polymerase chain reaction (PCR).
\end{abstract}

Key words: Atropa belladonna, hairy root, scopolamine, bioreactor

\section{INTRODUCTION}

Atropa belladonna L. (solonacea), generally referred to as the "deadly nightshade," is a perennial herbaceous plant used for commercial production of tropane alkaloids in the pharmaceutical industry (Zhang et al. 2005). Among tropane alkaloids, scopolamine is a more valuable secondary metabolite due to its fewer side-effects, usefulness in the treatment of Parkinson's disease, and relaxing and hallucinogenic properties. Many efforts have been made to extract scopolamine from the plants but because of the low endogenicity of scopolamine content, the commercial production of scopolamine is limited.

Because of their fast-growing genetic and biosynthetic stability, hairy root cultures are regarded as an effective method for biomass production in plant tissue culture (Yang et al.
2011). Hairy roots obtained from the transgenic plants using A. rhizogenes supply obvious contents of biological products and secondary metabolites (Dechaux and Boitel-Conti 2005). Genetically produced hairy roots not only increase high-value secondary metabolites, but can also perform with greater efficiency than nontransgenic roots (Kamada et al. 1986; Flores et al. 1999; Giri and Narasu 2000). The production of tropane alkaloids, especially scopolamine, in bioreactors instead of from native plants, is an efficient way because the process is performed under clean and controlled circumstances, which consequently controls or decreases the diversity in component quality and the alkaloid yield (Eibl et al. 2008).

Recently, the use of plant hairy roots for the production of various chemicals such as pharmaceuticals, pesticides, flavorings, and dyes has been taken into consideration. Plant hairy

*Author for correspondence: khpiri@gmail.com 
roots have proved valuable because of their great stability and productivity (Payne et al. 1992). They show indefinite and active proliferation in phytohormone-free media and are capable of producing valuable materials at similar or higher levels compared to original plant roots (Flores and Curtis 1992). Another advantage of plant hairy roots is the large-scale plant micro-propagation. This technique is an effective way of propagating massive amounts of disease-free plants and is genetically uniformed by "artificial" seeds, which can be achieved through direct organogenesis from hairy roots (Honda et al. 2001). Transformed root cultures provide a promising alternative to biotechnological exploitation and a method for constant and standard production of valuable metabolites of plant cells.

Several bioreactor designs for large-scale production of hairy roots have been reported (Nobuyuki and Takesh 1994; Nam 1996). Bioreactors used for hairy root cultures are more complex owing to the continuous growth of hairy roots. A bioreactor must have a unique configuration to compensate for the heterogeneous, cohesive, structured, and entangled nature of fibrous roots (Giri et al. 2000). In flask and bioreactor cultures, the oxygen transferred to hairy roots and submerged in the medium exhibits three external mass transfer resistances: gas-liquid, liquid-liquid, and liquidsolid resistances. In shake-flask cultures, the important parameters affecting flask properties are flask size, shaking speed, closure type, and medium volume (Auro et al. 1957).

Since the physical structure of hairy roots causes problems for making an efficient distribution during scale-up, productivity of hairy roots have been reported to decrease (Lee et al. 1999). Many factors can critically affect biomass and secondary metabolites production during scale-up of any kind of cell culture. These include aeration, agitation, $\mathrm{pH}$, temperature, and inoculum density (Humphery 1998; Kim et al. 2002).

Large-scale plant production through cell tissues in bioreactors is a key way for industrial plant propagation. In a biochemical context, bioreactors are usually explained as self-contained, sterile environments, which capitalize on liquid nutrient or liquid/air inflow and outflow systems. They are designed for intensive culture and providing maximal opportunity for monitoring and controlling micro-environmental conditions (e.g., agitation, aeration, temperature, dissolved oxygen,
$\mathrm{pH}$, etc.). Plant cell cultures are increasingly utilized for the production of valuable natural products such as pharmaceuticals, flavors, fragrances, and fine chemicals. More than 20,000 different chemicals are produced from the plants, and about 1,600 new plant chemicals are discovered each year (Sajc et al. 2000). On the other hand, various problems associated with low cell productivity, slow growth, genetic instability, and an inability to maintain photoautotrophic growth have limited the application of plant cell cultures (Bourgaud et al. 2001).

The use of bioreactors for culturing hairy roots is complex owing to the continuous growth of hairy roots. They must have a special configuration to compensate for the heterogeneous, structured, and entangled nature of fibrous roots (Taya et al. 1989). Hairy roots cultured in either shake flasks or bioreactors tend to distribute unevenly throughout the vessel and to form dense and highly tangled root clumps, which may resist flow by branching the growth pattern of hairy roots. Conditions in the interior of the clump may be very different from those of the bulk liquid due to mass-transfer effects. The nutrient limitation caused by the formation of dense root clumps leads to cell death and necrosis at the core of the root clumps (Yu and Doran 1994). The scale-up of hairy root cultures becomes complicated because of the need to simultaneously provide nutrients from both liquid- and gas- phases. To design the bioreactors for hairy root cultures many factors should be considered, such as the growth characteristics, nutrient requirements and utilization rates, mass transfer, mechanical properties, requirement of a support matrix, and the possibility of flow restriction by the root mass in certain parts of the bioreactor ( $\mathrm{Yu}$ and Doran 1994). Moreover, in order to obtain an optimal biomass yield, roots should be evenly distributed in the bioreactor (Honda et al. 2001).

Formation of aggregates, the tendency for cells to adhere to the walls of the fermenter vessel and sensitivity of hairy roots are significant challenges associated with the low amount of scopolamine production. Many studies have been conducted to industrialize the production of plant secondary metabolites in bioreactors; however, very few have attained commercial success. Building and handling bioreactors and controlling its conditions have proved costly. Therefore, this study aimed to develop the optimal conditions of aeration and agitation required for increasing the scopolamine 
productivity in hairy root of $A$. belladonna and to design and build a modified bioreactor to reduce the costs.

\section{MATERIALS AND METHODS}

\section{Plant materials and tissue culture}

Fresh seeds of $A$. belladonna were washed with running tap water for $20 \mathrm{~min}$. The seeds were then surface sterilized with $70 \%$ ethanol and subsequently treated with $2 \%$ sodium hypochlorite for 1 and $12 \mathrm{~min}$, respectively. Thereafter, the seeds were washed 3-4 times with sterile distilled water. Finally, these disinfected seeds were cultured on hormone-free MS/2 medium, containing $30 \mathrm{~g} \mathrm{~L}-1$ of sucrose in darkness. The medium was adjusted to $\mathrm{pH} 5.7$ and autoclaved at $121^{\circ} \mathrm{C}$ for $15 \mathrm{~min}$. Cultures were incubated at $26 \pm$ $1^{\circ} \mathrm{C}$ and maintained in $16 \mathrm{~h}$ light and $8 \mathrm{~h}$ dark periods.

\section{Preparation of $A$. rhizogenes}

A. rhizogenes ATCC 15834 (harboring pRi15834) was obtained from the National Institute of Genetic Engineering and Biotechnology (NIGEB), Tehran, Iran. It was cultured in liquid Luria Bertani medium containing $50 \mathrm{mg} / \mathrm{L}$ rifampicin, $10 \mathrm{~g} / \mathrm{L}$ tryptone, $5 \mathrm{mg} / \mathrm{L}$ yeast extract and $10 \mathrm{mg} / \mathrm{L}$ $\mathrm{NaCl}, \mathrm{pH} 7.2$ to an optical density of 0.6 at $28^{\circ} \mathrm{C}$ and $160 \mathrm{rpm}$ on a shaker incubator for $24 \mathrm{~h}$. The cells were pelleted by centrifugation at $3,000 \mathrm{rpm}$ for $15 \mathrm{~min}$ and re-suspended to a cell density of $\mathrm{OD}_{600}=8$ in liquid inoculation medium, consisting of MS salts and vitamins along with $50 \mathrm{mg} / \mathrm{L}$ sucrose.

\section{Hairy root induction and culture conditions}

Different seedling parts, including roots, stems and leaves (with petioles) were isolated from in vitro grown seedlings and were cut into explants. The explants were randomly wounded using sterile needle and inoculated with $A$. rhizogenes ATCC 15834 for $10 \mathrm{~min}$. The explants were dried with sterile filter paper and then transferred to cocultivation medium, which was $1 / 2$ MS medium. After two days of co-cultivation at $24^{\circ} \mathrm{C}$ in the dark, the explants were transferred onto a $1 / 2 \mathrm{MS}$ containing $300 \mathrm{mg} \mathrm{l}^{-1}$ cefotaxime to remove the residual Agrobacterium. Hairy roots of $A$. belladonna were produced after 10 days and cultivated in hormone - free MS/2 medium, containing $30 \mathrm{gL}-1$ of sucrose in darkness. They were sub-cultured every 15 days (Fig. 1).

Hairy roots obtained from a single clone were transferred onto a $100 \mathrm{~mL}$ MS liquid medium in $250 \mathrm{~mL}$ flasks, kept at $110 \mathrm{rpm}$. This clone was selected on the basis of fast growth and shape. The culture was sub-cultured every three weeks

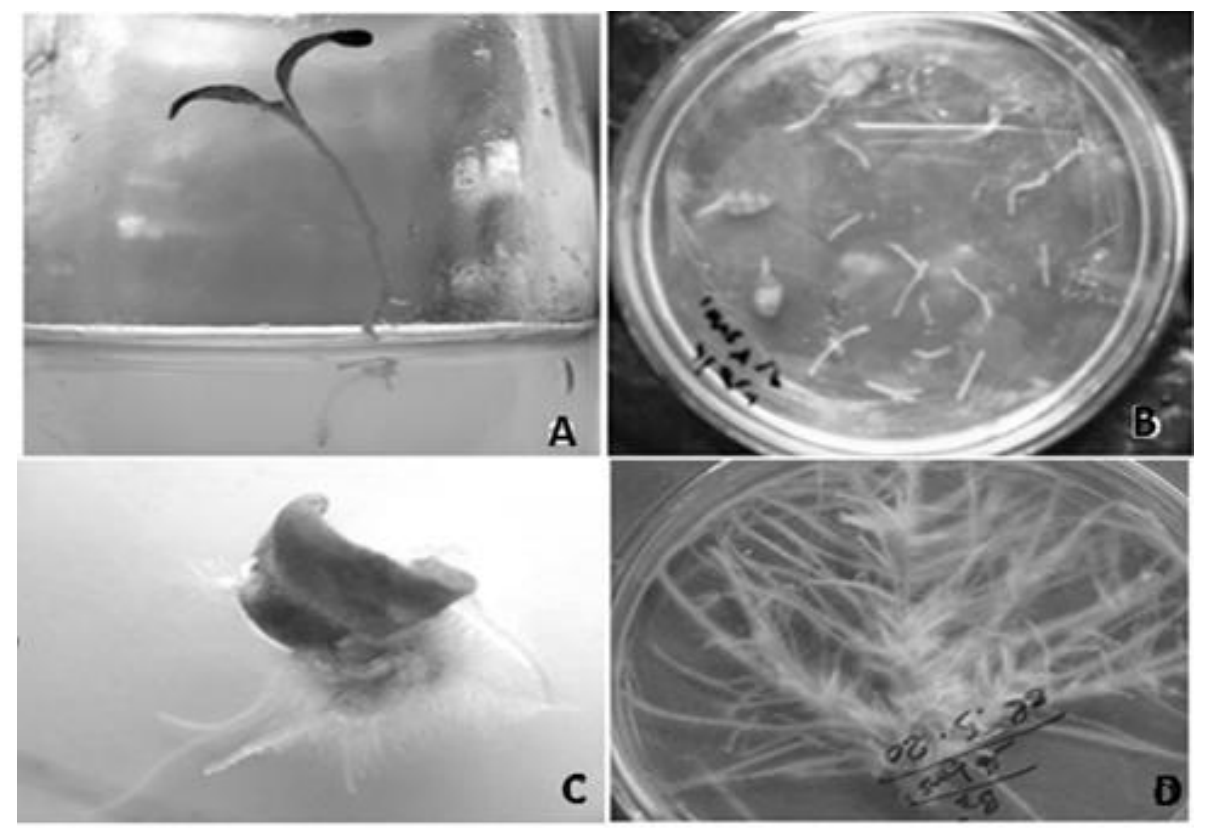

Figure 1 - A -Seedlings of Atropa belladonna $(B)$. Different seedling parts including roots, stems and leaves (C). Hairy root induction from wounded sites. (D) The cultivated hairy root in hormone - free MS/2 medium. 


\section{Polymerase chain reaction analysis}

Extraction of genomic DNA from the hairy roots and normal roots (control) of A. belladonna was performed as per the protocol of CTAB (Cai et al. 1997). The DNA samples obtained were subjected to PCR amplification with specific primers for the presence of the rolB gene (forward primer 5'ATGGATCCCAAATTGC TATTCCCCCACGA-3' and reverse primer 5'TTAGGCTTCTTTCATTCGGTTTACTGCAGC-3').

\section{Hairy root cultures}

\section{Hairy root cultures in shake flask}

Ten days old hairy roots of $A$. belladonna were inoculated in $250 \mathrm{~mL}$ flasks containing $100 \mathrm{~mL}$ of a MS/2 medium. The average inoculums rate was $0.5 \pm 0.01 \mathrm{~g}$ fr. wt. The hairy root cultures were also maintained on a $1 / 2$ MS liquid medium on a rotary shaker $(110 \mathrm{rpm})$ in complete darkness for transfer to bioreactor in next step.

\section{Hairy root culture in the bioreactor}

In this study, a bioreactor was made of a glass vessel $(30 \mathrm{~cm}$ in height and $14 \mathrm{~cm}$ in diameter) with a working volume of $1.5 \mathrm{~L}$. An autoclavable lid was equipped with sampling port and air outlet and inlet ports. The lid was sealed to the vessel by an o-ring and a baffle with two impellers $(10 \mathrm{~cm}$ in height and $3 \mathrm{~cm}$ in diameter), joined strongly by coupling to the lid. The air was supplied through an autoclavable plastic tube into the vessel. Supplied air was sterilized by passing through an air filter in air outlet and inlet ports. Then, a stainless steel mesh, $10 \mathrm{~cm}$ in height and $5 \mathrm{~cm}$ in diameter, with pores of $0.5 \mathrm{~cm}$ was placed in the vessel and connected to the bottom of the lid to reduce the shear damage of impellers and bubbles, which inhibited the contact between impellers and hairy roots. Hairy roots $(0.5 \mathrm{~g}$ fr. wt) were inoculated in the bioreactor and the effect of various conditions of agitation $(40,70,110 \mathrm{rpm})$ and aeration $(0.75,1.25,1.75 \mathrm{vvm})$ on biomass and scopolamine production were studied (Table 1).

\section{Measurement of conductivity, sugar content, and biomass}

The electrical conductivity of the culture medium was measured using an electrical conductivity electrode manufactured by Metrohm. Sugar reduction was measured by a calorimetrical using the 3,5-dinitrosalicylic acid (DNS) method (Miller 1995) by a spectrophotometer (Lambda
45UV/Visible). To measure the fresh and dry weights, hairy roots from the bioreactor were harvested, dried between four Whatman filter paper and then weighed. The growth index was determined using the formula $(\mathrm{Wd}-\mathrm{Wi})$, where Wd was the final dry weight of the culture after 28 days and Wi was the initial dry weight of the culture.

Table 1 - Different aeration and agitation conditions in the bioreactor.

\begin{tabular}{ccc}
\hline Device number & Agitation (rpm) & Aeration vv (n) \\
\hline 1 & & 0.75 \\
2 & 40 & 1.25 \\
3 & & 1.75 \\
4 & & 0.75 \\
5 & 70 & 1.25 \\
6 & & 1.75 \\
7 & & 0.75 \\
8 & \multirow{2}{*}{110} & 1.25 \\
9 & & 1.75 \\
\hline
\end{tabular}

\section{Extraction of alkaloids and HPLC analysis}

In order to quantify the total scopolamine, $100 \mathrm{mg}$ of powdered dry hairy roots were soaked in 5.0 $\mathrm{mL}$ of chloroform - methanol-ammonia $(25 \%)$ $(15: 5: 1 ; \mathrm{v} / \mathrm{v} / \mathrm{v})$, sonicated in an ultrasonic cleaning bath for $90 \mathrm{~min}$. and centrifuged at $6,000 \mathrm{~g}$ for 5 min. The extraction was adjusted at $\mathrm{pH} 10-12$ using ammonia. The organic phase was evaporated under gaseous $\mathrm{N}_{2}$, and the residue was dissolved in $2.0 \mathrm{~mL}$ methanol, then filtered using a $0.4 \mu \mathrm{m}$ filter (Kamada 1986). HPLC analysis and quantification of the scopolamine were conducted according to Zarate et al. (1997). Mobile phase consisted of methanol and $0.05 \mathrm{~mol} / \mathrm{L}$ ammonium acetate solution (added with $0.0025 \mathrm{~mol} / \mathrm{L} \mathrm{SDS}$ ) at a ratio 58:42, with flow rate of $1.0 \mathrm{~mL}$ per min and detecting wavelength as $226 \mathrm{~nm}$. The sample solution of injection was $20 \mu \mathrm{L}$ each time.

\section{Statistical analysis}

A completely randomized experimental design with $3 \times 3$ factorial arrangement was applied. Each treatment was repeated three times. Variations among treatments were analyzed using Duncan's multiple range test and $P<0.05$ was considered significant.

\section{Chemicals}

Scopolamine was purchased from Sigma Chemical Co. (St. Louis, MO, USA). Chloroform, methanol, and sulfuric acid were purchased from Merck. 


\section{RESULTS AND DISCUSSION}

To confirm the transgenic hairy roots production, a PCR analysis was performed using specific primers rolB gene. Results showed that there were diagnostic bands, $780 \mathrm{bp}$ in size, related to the specific reproduction of rolB gene, thus showing the production of transgenic lines (Fig. 2 ).

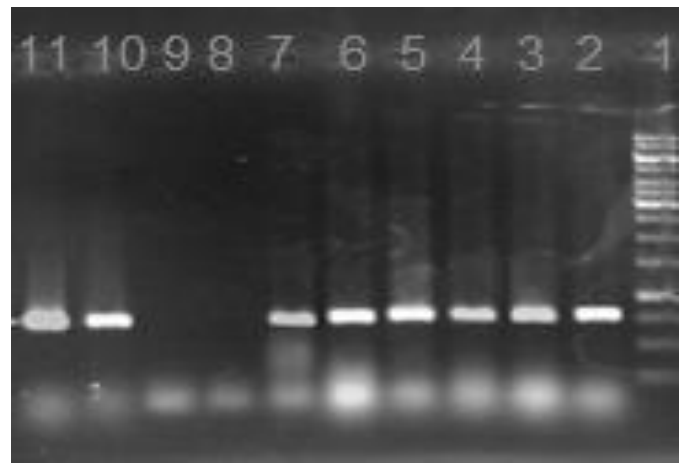

Figure 2 - PCR analysis for the detection of the rolB gene in hairy roots to confirm transformation. Lane $1=$ molecular weight marker (1000 bp ladder); lane 2, 3,4,5,6,7 = DNA from transformed explants; lane $8,9=$ none transformed explants (non positive control); lane $10,11=$ Agrobacterium rhizogenes DNA (positive control).

Studies on the effect of agitation and aeration in bioreactors on biomass and scopolamine content in hairy roots showed their significant effects on both the fresh and dry weight of hairy roots and scopolamine production (Table 2).
Table 2 - The effects of different aeration and agitation conditions on biomass and scopolamine production in hairy roots after culturing for 28 days.

\begin{tabular}{ccccc}
\hline \multirow{2}{*}{$\begin{array}{c}\text { Aeration } \\
(\mathbf{v v m})\end{array}$} & $\begin{array}{c}\text { Agitation } \\
(\mathbf{r p m})\end{array}$ & \begin{tabular}{c} 
BW $(\mathbf{g})$ \\
\cline { 3 - 4 }
\end{tabular} & $\mathbf{D W}(\mathbf{g})$ & $\begin{array}{c}\text { Scopolamine } \\
\text { content } \\
\left(\mathbf{m g ~ g ^ { - 1 }} \mathbf{d w}\right)\end{array}$ \\
\hline 0.75 & 40 & $9.56^{\mathrm{d}}$ & $0.716^{\mathrm{c}}$ & $0.77^{\mathrm{d}}$ \\
0.75 & 70 & $10.42^{\mathrm{c}}$ & $0.814^{\mathrm{c}}$ & $1.12^{\mathrm{c}}$ \\
0.75 & 110 & $8.6^{\mathrm{e}}$ & $0.69^{\mathrm{c}}$ & $0.7^{\mathrm{e}}$ \\
1.25 & 40 & $14.3^{\mathrm{b}}$ & $0.95^{\mathrm{b}}$ & $1.3^{\mathrm{b}}$ \\
1.25 & 70 & $16.63^{\mathrm{a}}$ & $1.289^{\mathrm{a}}$ & $1.59^{\mathrm{a}}$ \\
1.25 & 110 & $6.01^{\mathrm{fg}}$ & $0.36^{\mathrm{d}}$ & $0.66^{\mathrm{f}}$ \\
1.75 & 40 & $6.3^{\mathrm{f}}$ & $0.28^{\mathrm{d}}$ & $0.46^{\mathrm{g}}$ \\
1.75 & 70 & $5.5^{\mathrm{g}}$ & $0.32^{\mathrm{d}}$ & $0.39^{\mathrm{h}}$ \\
1.75 & 110 & $2.5^{\mathrm{h}}$ & $0.11^{\mathrm{e}}$ & $0.135^{\mathrm{i}}$ \\
\hline
\end{tabular}

Means followed by different letters within a column are significantly different at $\mathrm{P}<0.05$ by Duncan's multiple range test. Each treatment was repeated three times.

Table 2 showed that after 28 days, the highest fresh and dry weight were 16.63 and $1.28 \mathrm{~g}$, respectively. The scopolamine content obtained was $1.59 \mathrm{mg} \mathrm{g}^{-1}$ dry wt in the bioreactor with agitation $70 \mathrm{rpm}$ and aeration $1.25 \mathrm{vvm}$. After 30 days, the dry weight of hairy roots had increased 58 times the initial dry weight in the bioreactor with agitation $70 \mathrm{rpm}$ and aeration $1.25 \mathrm{vvm}$. Also, the fresh weight, dry weight and scopolamine content were $2.5 \mathrm{~g}, \quad 0.11 \mathrm{~g}, \quad$ and $0.135 \mathrm{mg} \mathrm{g}^{-1}$ dry wt, respectively, with aeration $1.75 \mathrm{vvm}$ and agitation $110 \mathrm{rpm}$ (Fig. 3A). In the bioreactor with agitation $(110 \mathrm{rpm})$ and aeration $(1.75 \mathrm{vvm})$, the lowest fr wt, dry wt, and the scopolamine content achieved were $2.5 \mathrm{~g}, 0.11 \mathrm{~g}$, and $0.135 \mathrm{mg} \mathrm{g}^{-1}$ dry wt, respectively (Fig. 3B).

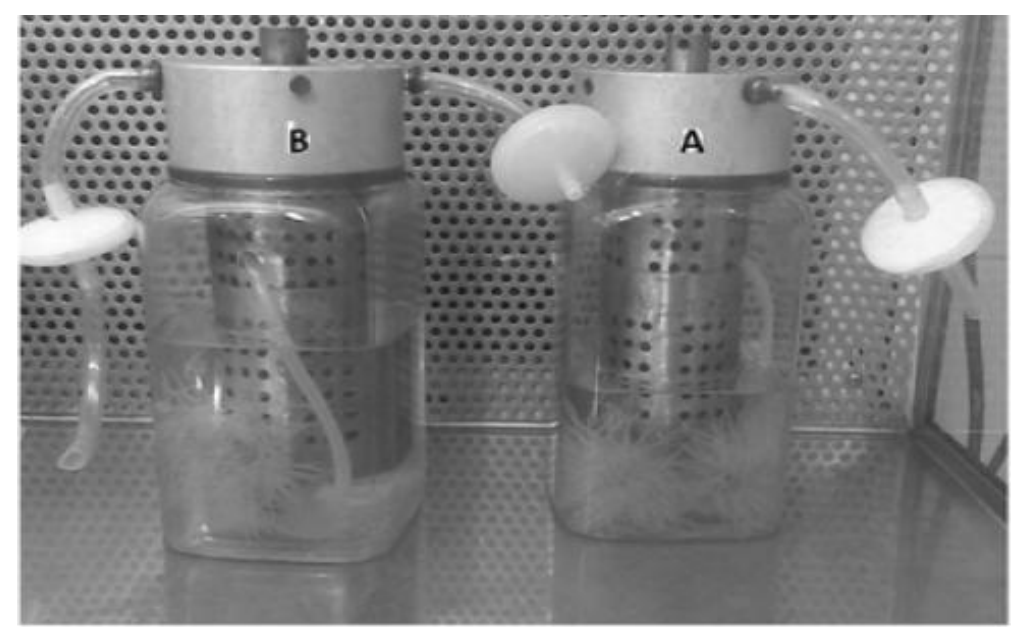

Figure 3 - (A) Bioreactor with agitation $70 \mathrm{rpm}$ and aeration $1.75 \mathrm{vvm}$ (B) Bioreactor with agitation $110 \mathrm{rpm}$ and $1.75 \mathrm{vvm}$. 
The factors enhancing the production of biomass and secondary metabolites must be considered in the designing the bioreactors (Chattopadhyay et al. 2002). During the early stage of growth, DO concentration decreases drastically. The air -flow needed for the bioreactor settles the level of aeration and agitation and reduces settling of the biomass, hence influencing the growth and secondary metabolites production. With the increase of cell density, higher rates of aeration are required. The present study indicated that hairy roots of A. belladonna required high concentration of aeration compared to other root cultures and plant cells.

Scopolamine production is dependent on aeration such that the oxygen molecules activate one of the important key enzymes (6b-hydroxyhyoscyamine) in scopolamine production in plant cells and tissue cultures (Hashimoto et al. 1989; Min et al. 2007; Kardilo et al. 2010). Improvements in $\mathrm{H} 6 \mathrm{H}$ activity causes more hyosiamine to change into scopolamine (Palazon et al. 2003). When aeration level is low, cells decline energy (ATP) levels, which may direct affect the cellular metabolism and morphology (Leathers 1995). Smart and Fowler (1984) cultivated Catharanthus roseus in an airlift reactor using aeration rates in the range 0.33 to $1.33 \mathrm{vvm}$. Aeration rate up to $0.66 \mathrm{vvm}$ resulted in 40 to $70 \%$ increases in biomass, but biomass was reduced by $38 \%$ at an aeration rate of $1.33 \mathrm{vvm}$ (Kim 1994).

Due to direct oxygen toxicity, high aeration results in decrease of cell growth and scopolamine production (Schlatmann et al. 1993). Also, excessive aeration increases the moval of $\mathrm{CO}_{2}$, ethylene or other gaseous compounds that are important for cell growth and secondary metabolites production ( $\mathrm{Pan}$ et al. 2000). $\mathrm{CO}_{2}$ leads to the penetrability of the cellular membrane, enzymatic activities, and the secretion of intracellular hormones. Under low $\mathrm{CO}_{2}$ conditions, the activities of enzymes of carbohydrate metabolism, including phosphofructokinase and glucose-6-phosphate-dehydrogenase were reduced. The enzyme levels increased when $\mathrm{CO}_{2}$ was kept constant and then the cell growth rose rapidly (Stuhfauth 1987). When the bioreactor was operated at $1.75 \mathrm{vvm}$, a turbulent flow was produced, and the hairy roots were covered with foam.

High agitation results in shear damage, the cell wall collapses; hence cell death. Cell death causes foaming, adhesion of the cell, and aggregation of the culture vessel walls. Thus, this leads to the interruption of the homogeneous culture conditions in the bioreactor, which subsequently affects secondary metabolites (Scragg 2007). Present study showed that high agitation and aeration of $110 \mathrm{rpm}$ and $1.75 \mathrm{vvm}$, respectively caused foaming and decreased biomass and scopolamine production.

Inadequate agitation leads to the clumping of cells, thereby, it complicates the nature of the reaction system. Also, the inner cells of the clumps become nutrient deficient, which may have either an adverse or a positive effect on the cell growth and production. Ho et al. (1995) reported that high agitation ranges (100-325 rpm) with excessive aeration rates decreased biomass. In general, gentle mixing improves oxygen transfer and nutrients into the bioreactor and it can influence biomass and secondary metabolites production. The scopolamine content is comparable to the one reported in the flask culture and bioreactor, while the amount of scopolamine achieved was very high than that case. Lee et al. (1999) reported scopolamine content as $1.1 \mathrm{mg} / \mathrm{g}$ dry wt of the cultivated hairy roots of atropa belladonna in 3-1 modified stirring bioreactor with agitation $100 \mathrm{rpm}$ and aeration $0.3 \mathrm{vvm}$ after one month. Cardilo et al. (2010) found that the scopolamine content of cultivated hairy roots of Brugmansia candida cultured in the agitation tank's bioreactor had changed and the flask culture was 1.05 and 0.5 $\mathrm{mg} / \mathrm{g}$ dry wt.

The previous studies have shown that a gradual rise in the aeration volume is effective for root growth in bioreactors because the high inflows of the air agitate the cells, thereby increasing the concentration of the dissolved oxygen around the cell and in the medium. Despite this, high aeration volumes throughout the culture period inhibit cell growth, which is itself due to shear stress (Jeong et al. 2006; Lee et al. 2006). Notwithstanding, a high volume doesn't always enhance the accumulation of compounds in plant cultures. Min et al. (2007) reported higher biomass production from Scopolia parviflora when cultured in a high aeration volume (0.4 vvm), but increased alkaloid contents at a lower volume $(0.1 \mathrm{wm})$. These results suggested that the aeration volume should be adjusted based on the selected ex-plant source and the cultural stage for biomass production. Present study showed that proper aeration and agitation 
preserved the optimum culture conditions for enhancing cell growth and increased scopolamine production in bioreactor cultures.

Sugar consumption and variation of medium conductivity were measured during hairy root growth. Figure 4 showed that conductivity of the medium decreased under all agitation and aeration conditions. However, the highest medium conductivity belonged to the bioreactor with agitation $110 \mathrm{rpm}$ and aeration $1.75 \mathrm{vvm}$, but the lowest medium conductivity was achieved in with $70 \mathrm{rpm}$ agitation and $1.25 \mathrm{vvm}$ aeration.

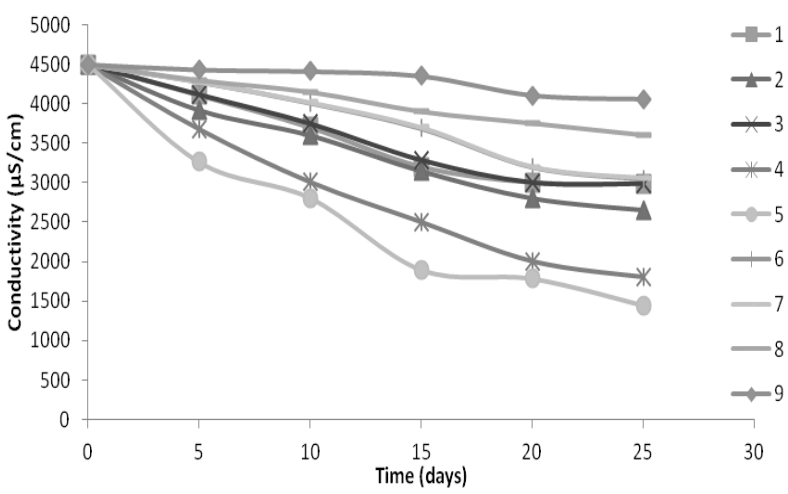

Figure 4 - Medium conductivity of hairy roots during the 30-day culture1 (40rpm,0.75vvm), 2 (40rpm,0.1.25vvm), 3 (40rpm,1.75vvm), 4 (70rpm,0.75vvm), 5 (70rpm, $1.25 \mathrm{vvm}), 6$ (70rpm, 1.75vvm), 7(110rpm, 0.75vvm), 8 (110rpm, 1.25vvm), 9 (110rpm, 1.75vvm).

The measurement of medium conductivity is suitable to estimate cell growth in tissue cultures and plant cells (Zhong et al. 2000). Palazon et al. (2003) reported that there was a linear correlation between biomass increase and medium conductivity decrease in plant cell cultures in the bioreactor medium. This could be due to nutrient consumption in the culture medium. Hairy root growth requires high nutrition concentration during the growth period.

Figure 5 presents information on sucrose content changes during the growth period under different bioreactor conditions.

The highest sucrose consumption and consequently reduced sugars, including glucose and fructose, was achieved in the bioreactor with $70 \mathrm{rpm}$ agitation and $1.25 \mathrm{vvm}$ aeration. Sucrose has been reported as an important factor affecting the production of alkaloids in the culture medium (Zhang et al. 1996). In general, sucrose is quickly consumed from the culture medium and after 10-
15 days, it could be 5- $10 \mathrm{~g} \mathrm{~L}^{-1}$ from an initial concentration of $30 \mathrm{~g} \mathrm{~L}^{-1}$. Jeong et al. (2006) reported that after 10 days of cultivating hairy roots of ginseng in the bioreactor, sucrose concentration decreased rapidly and at this time, fructose and glucose were significantly increased in the medium. Sucrose was hydrolyzed into glucose and fructose by the invertase released by the hairy roots and then glucose and fructose were used equally by hairy roots during the cell growth.

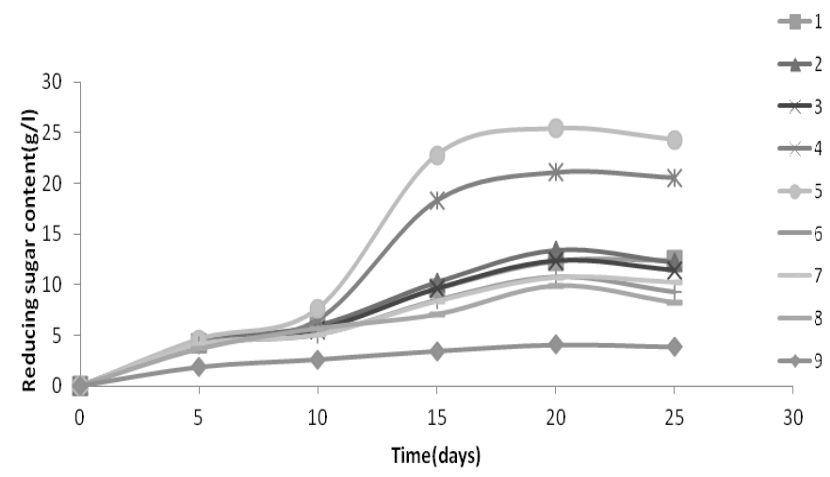

Figure 5 - Changes in sugar's decreasing content in different conditions of agitation and aeration $1(40 \mathrm{rpm}, 0.75 \mathrm{vvm}), 2$ (40rpm, $0.1 .25 \mathrm{vvm}), \quad 3 \quad(40 \mathrm{rpm}, 1.75 \mathrm{vvm}), \quad 4$ (70rpm,0.75vvm), 5 (70rpm, $1.25 \mathrm{vvm}), 6$ (70rpm, 1.75vvm), 7 (110rpm, 0.75vvm), 8 (110rpm, $1.25 \mathrm{vvm}), 9$ (110rpm, $1.75 \mathrm{vvm})$.

Also, glucose may act directly as signaling molecules in some sugar-response pathways (Sivakumar et al. 2005). Sugars act in regulating the expression of important plant root genes (Koch et al. 1996). For example, a calcium-dependent protein, kinase acts in sugar-regulated gene expression in the plants (Ohto et al. 1995). Krapp et al. (1993) reported that although sucrose and glucose could act directly as signaling molecules in some sugar-response pathways, other pathways might sense the level of a different sugar or sugar metabolite. In addition, some sugar-response pathways may sense the rate of flux through a particular metabolic pathway, rather than the absolute levels of sugars or sugar metabolites.

\section{CONCLUSION}

In conclusion, the insertion of native $A$ rhizogenesT-DNA in $A$. belladonna genome 
worked successfully. The generated transgenic hairy roots were scaled-up successfully using a modified system for the production of scopolamine by $A$. belladonna. The bioreactor with aeration and agitation $1.25 \mathrm{vvm}$ and $70 \mathrm{rpm}$ provided optimal conditions for the production of scopolamine. Therefore, this kind of bioreactor could be used for commercial production of valuable secondary metabolites on large-scale. Some significant characteristics of this system were as follows: (1) its characteristic configuration would not degrade upon scale-up, (2) nutrients and oxygen were accessible in sufficient concentrations to the roots throughout the reaction volume.

\section{ACKNOWLEDGMENT}

This work was supported by Bu-Ali Sina University of Hamedan. We would like to thank Pars Supap Factory for helping us build in building the bioreactors.

\section{REFERENCES}

Auro MA, Hodge HM, Roth NG. Oxygen Absorption Rates in Shaken Flasks. Ind Eng Chem. 1957; 49: 1237-1238.

Bourgaud F, Gravot A, Milesi S, Gonteir E. Production of plant secondary metabolites: a historical perspective. Plant Sci. 2001; 161: 839-851.

Cai D, Kleine M, Kifle S, Horloff HJ, Sandal NN, Marcker KA, Lankhorst RMK, Salentijn EMJ, Lange W, Stiekema WJ, Wyss V, Grundler FMW, Jung C. Positional cloning of a gene for nematode resistance in sugarbeet. Science. 1997; 275: 832-834.

Cardillo AB, Otalvarob AM, Bustoa VD, Taloua JR, Velasquez ME, Giulietti AM. Scopolamine, anisodamine and hyoscyamine production by Brugmansia candida hairy root cultures in bioreactors. Biochem. 2010; 45: 1577-1581.

Chattopadhyay S, Farkya S, Srivastava AK, Bisaria VS. Bioprocess considerations for production of secondary metabolites by plant cell suspension cultures. Biotechnol Bioprocess Eng. 2002; 7: 138149.

Dechaux C, Boitel-Conti M. A strategy for overaccumulation of scopolamine in Dature innoxia hairy root culture. Acta Biol Crac. 2005; 47: 101-107.

Eibl R, Eibl, D. Design of bioreactors suitable for plant cell and tissue cultures. Phytochem Rev. 2008; 7: 593 598.
Flores HE, Curtis WR. Approaches to understanding and manipulating the biosynthetic potential of plant roots. Proc NY Acad Sci. 1992; 655: 188-209.

Flores HF, Vivanco JM Loyola-Vargas VM. Radicle biochemistry: the biology of root-specific metabolism. Trends Plant Sci.1999; 4: 220-226.

Giri A, Narasu ML. Transgenic hairy roots: recent trends and applications. Biotechnol Adv. 2000; 18: 122.

Hashimoto T, Kohno J, Yamada Y. 6bHydroxyhyoscyamine epoxidase from cultured roots of Hyoscyamus Niger. Phytochemistry. 1989; 28: 1077-1082.

Ho CH, Henderson KA, Rorrer GL. Cell-damage and oxygen mass transfer during cultivation of Nicotiane tabacum in a stirred tank bioreactor. Biotechnol Prog. 1995; 11:140-145.

Honda H, Liu C, Kobayashi T. Large-scale plant micropropagation. Adv Biochem Eng Biotech. 2001; 72: $157-82$.

Hooykaas PJJ, Schilperoort RA. Agrobacterium and plant genetic engineering. Plant Mol Biol. 1992;19: 15-38.

Humphery A. Shake flask to fermentor: what have we learned? Biotechnol Prog. 1998; 14: 3-7.

Jeong CS, Chakrabarty D, Hahn EJ, Lee HL, Paek KY. Effects of oxygen, carbon dioxide and ethylene on growth and bioactive compound production in bioreactor culture of ginseng adventitious roots. Biochemical Engr J. 2006; 27: 252-263.

Kamada H, Okamura N, Satake M, Harada H, Shimomura K. Alkaloid Production by Hairy Root Cultures in Atropa belladonna. Plant Cell Rep. 1986; 5: 239-242.

Kim YH. Effects of Light and Antioxidants on Betalain and Phytolaccoside Formation in Hairy Roots of Phytolacca esculeuta VAN HOUTTE. Ph.D. Thesis.

Kim Y, Wyslouzil B, Weathers P. Secondary metabolism of hairy root cultures in bioreactors. In Vitro Cell. Dev Biol Plant. 2002; 38: 1-10.

Koch KC. Carbohydrate-modulated gene expression in plants. Annu Rev Plant Physiol Plant Mol Biol.1996; 47: 509-540.

Kondo O, Honda H, Taya M, Kobayashi T. Comparison of growth properties of carrot hairy root in various bioreactors. Appl Microbiol Biotechnol.1989; 32: 291-294.

Krapp A, Hofmann B, Schäfer C, Stitt M. Regulation of the expression of $\mathrm{rbcS}$ and other photosynthetic genes by carbohydrates: a mechanism for the 'skin regulation' of photosynthesis. Plant J. 1993; 3: 817828.

Leathers RR, Smith MAL and Christie AJ. Automation of the bioreactor process for mass propagation and secondary metabolism. 1995 In: Christie JA, Kozai T, Smith ML (eds) Automation and Environmental Control in Plant Tissue Culture). Kluwer Academic Publishers, Dordrech. pp. 187-214. 
Lee KT, Suzuki T, Yamakawa T, Kodama T, Igarashi Y, Shimomura K. Production of tropane alkaloids by transformed root cultures of Atropa belladonna in stirred bioreactors with a stainless steel net. Plant Cell Rep. 1999; 18: 567-571.

Miller GL. Use of dinitrosalicyclic acid reagent for determination of reducing sugar. Anal Chem.1959; 31: 426-428.

Min JY, Jung HY, Kang SM, Kim YD, Kang YM, Park DJ, Prasad DT, Choi MS. Production of tropane alkaloids by small-scale bubble column bioreactor cultures of Scopolia parviflora adventitious roots. Bioresource Technol. 2007; 98: 1748-1753.

Nam KY. Contemporary Korean ginseng: chemical constituents and pharmacolgical activity. Daejeon: Korean Ginseng and Tobacco Research Institute. 1996

Nobuyuki V, Takesh K.1994 in: Ryu DDY, Furusaki S, (Eds.). Advances in Plant Biotechnology, Elsevier, Amsterdam, The Netherlands, pp. 307-338.

Ohto M, Nakamura K. Sugar induced increase of calcium dependent protein kinases associated with the plasma membrane in leaf tissues of tobacco. Plant Physiol. 1995; 109: 973-981.

Palazon J, Mallol A, Eibl R, Lettenbauer C, Cusido RM, Pinnol MT. Growth and Ginsenoside Production in Hairy Root Cultures of Panax ginseng using a novel Bioreactor. Planta Med. 2003; 69:344-9.

Pan ZW, Wang HQ, Zhong JJ. Scale-up study on suspension cultures of Taxus chinensis cells for production of taxane diterpene. Enzyme Microbiol Technol. 2000; 27: 714-723.

Payne GF, Bringi V, Prince CL, Shuler ML. Plant cell and tissue culture in liquid systems. Hanser, New York. 1992.

Sajc L, Grubisic D, Novakovic GV. Bioreactors for plant engineering: an out for further research. Biochem Eng J. 2000; 4: 89-99.
Schlatmann JE, Nuutila AM, Gulik WM, Hoopen HGJ, Verpoorte R, Heijhen JJ. Scale up of ajmalicine production by plant cell cultures of Catharanthus roseus. Biotechnol Bioeng. 1993; 41: 253-262.

Scragg AH. The Production of Flavours by Plant Cell Cultures. in Berger, R.G. (Ed.), Flavours and Fragrances, Springer, Berlin. 2007; 599-614.

Sivakumar G, Yu KW, Peak KY. Production of biomass adventitious root of Panax ginseng in bioreactor culture. Eng Life Sci. 2005; 5:333-342.

Stuhfauth T, Klug K, Fock HP. The production of secondary metabolites by Digitalis lanata during $\mathrm{CO} 2$ enrichment and water stress, Phytochemistry. 1987; 26: 27-35.

Taya M, Yoyama A, Kondo O, Matsui C. Growth characteristics of plant hairy roots and their cultures in bioreactors. J Chem Eng Japan. 1989; 22: 84-89.

Yang CH, Chen M, Zeng L, Zhang LE, Liu X, Lan X, Tang KE, Liao ZH. Improvement of tropane alkaloids production in hairy root cultures of Atropa belladonna by overexpressing pmt and h6h genes. POJ. 2011; 4: 29-33.

$\mathrm{Yu}$ S, Doran PM. Oxygen requirements and mass transfer in hairy root culture. Biotechnol Bioeng. 1994;44; 880-887.

Zarate R, Hermosin B, Cantos M, Troncoso A. J. Tropane alkaloid distribution of Atropa baetica plant Chem. Ecol. 1997; 23: 2059-2066.

Zhang L, Kai GY, Lu BB, Zhang HM, Tang KX, Jiang $\mathrm{JH}$, Chen WS. Metabolic engineering of tropane alkaloid biosynthesis in plants. J Integr Plant Biol. 2005; 47: 136-143.

Zhang YH, Zhong JJ, Yu JT. Enhancement of ginseng saponin production in suspension cultures of Panax notoginseng: manipulation of medium sucrose. $J$ Biotechnol. 1996; 51: 49-56. 